\title{
Digestibilidade total e degradabilidade ruminal in situ de dietas volumosas com inclusão de ionóforo ou probiótico para bubalinos e bovinos
}

\section{Total digestibility and in situ degradability of bulky diets with the inclusion of ionophores or probiotics for cattle and buffaloes}

\author{
Lúcia Maria Zeoula ${ }^{1}$; Odimári Pricila Pires do Prado²; \\ Luiz Juliano Valério Geron ${ }^{3 *}$; Juliano Ricardo Fontanini Beleze ${ }^{4}$; \\ Sílvia Cristina Aguiar³; Emilyn Midori Maeda ${ }^{5}$
}

\begin{abstract}
Resumo
Avaliaram-se os efeitos de ionóforo (monensina sódica) e de probiótico (Saccharomyces cerevisae + selênio + cromo) em dietas com $80 \%$ de volumoso sobre a digestibilidade aparente dos nutrientes. Utilizaram-se três búfalos, da raça Murrah (Bubalus bubalis) e três bovinos, da raça Holandesa (Bos taurus), com peso médio de $520 \pm 30 \mathrm{~kg}$ e $480 \pm 182 \mathrm{~kg}$, respectivamente, portadores de cânula ruminal, distribuídos em delineamento experimental com dois quadrados latinos $3 \times 3$, com arranjo fatorial $3 \times 2$, sendo, a ausência ou presença de aditivos: ionóforo ou probiótico e duas espécies. O indicador interno do fluxo fecal de matéria seca (MS) foi a cinza insolúvel em ácido. Foi conduzido ensaio de degradabilidade ruminal da MS, proteína bruta (PB) e fibra em detergente neutro (FDN) do feno de Tifton 85 para búfalos e bovinos. A dieta contendo probiótico apresentou maiores coeficientes de digestibilidade da matéria seca e matéria orgânica em bubalinos e bovinos, indicando um bom desempenho em dietas volumosas. A degradabilidade potencial e efetiva da matéria seca em búfalos na dieta com probiótico foi inferior ao ionóforo sugerindo que houve melhor digestão dos nutrientes no intestino grosso destes animais. A degradabilidade potencial e efetiva da fibra em detergente neutro e proteína bruta na dieta contendo ionóforo foram superiores à dieta contendo probiótico. Bubalinos apresentaram maior capacidade de digestão de matéria seca e fração fibrosa do que bovinos.
\end{abstract}

Palavras-chave: Aditivos, levedura, monensina sódica

\begin{abstract}
The effects of ionophores (monensin) and probiotic (Saccharomyces cerevisiae + selenium + chromium) in diets with $80 \%$ forage were evaluated on the digestibility of nutrients. Three buffaloes, Murrah (Bubalus bubalis) and three cattle, Holstein (Bos taurus), with an average weight of $520 \pm 30 \mathrm{~kg}$ and $480 \pm 182 \mathrm{~kg}$, respectively, with rumen cannula, over experimental design with two 3 × 3 Latin squares in a $3 \times 2$ factorial arrangement, with the absence or presence of additives: ionophore or probiotic and two species, were used. The internal flow indicator of fecal dry matter (DM) was the acid insoluble ash. DM, crude protein (CP) and neutral detergent fiber (NDF) ruminal degradability of Tifton 85 hay

\footnotetext{
${ }^{1}$ Prof ${ }^{a}$, Universidade Estadual de Maringá, UEM, Maringá, PR. E-mail: 1mzeoula@uem.br

2 Prof $^{\mathrm{a}} \mathrm{Dr}^{\mathrm{a}}$, Dept ${ }^{\mathrm{o}}$ de Zootecnia, Universidade Estadual de Londrina, UEL, Londrina, PR. E-mail: odimari@hotmail.com

${ }^{3}$ Profs., Universidade do Estado de Mato Grosso, UNEMAT, Pontes e Lacerda, MT. E-mail: ljgeron@unemat.br; scaguiar@ unemat.br

${ }^{4}$ Dr. em Produção de Ruminantes, TSM/Tortuga, Maringá, PR. E-mail: jbeleze@hotmail.com

${ }^{5}$ Prof $^{a}$, Universidade Tecnológica Federal do Paraná, UTFPR, Dois Vizinhos, PR. E-mail: maedazoo@yahoo.com.br

* Autor para correspondência
} 
was conducted for cattle and buffaloes. A diet containing probiotics had higher dry matter and organic matter digestibility in buffalo and cattle, indicating a good performance in bulky diets. The potential and effective dry matter degradability in diet with probiotic in buffaloes, were smaller than diet with ionophore, suggesting that there was a better digestion of nutrients in the intestine of these animals. The potential and effective degradability of neutral detergent fiber and crude protein in the diet containing ionophores were superior than diet containing probiotic. Buffaloes showed higher capacity of dry matter and fiber digestion than cattle.

Key words: Additive, sodic monensin, yeast

\section{Introdução}

A energia e a proteína da dieta são os principais fatores que afetam o crescimento e a eficiência das bactérias ruminais, contudo, outros fatores contribuem com a fermentação ruminal, como o pH e taxa de passagem, que são resultado do nível de consumo, qualidade e proporção do volumoso na dieta total, tipo e processamento dos carboidratos dos alimentos (VAN SOEST, 1994).

Para Sampaio, Vieira e Brito (2000), os ruminantes têm a capacidade peculiar de aproveitar alimentos fibrosos, inadequados ao consumo humano, convertendo-os em substâncias nutritivas que são aproveitadas para produção de carne, leite, lã e trabalho. Este processo depende intimamente da fermentação ruminal realizada pelos microrganismos que habitam os pré-estômagos do animal, os quais requerem energia e proteína em quantidade e qualidade adequadas a sua demanda metabólica para hidrólise e digestão de moléculas complexas como, por exemplo, a celulose.

O ionóforo tem sido utilizado na alimentação de bovinos de corte por mais de 20 anos para aumentar a eficiência alimentar (GOODRICH et al., 1984; RUSSELL; STROBEL, 1988). A monensina sódica é mais eficiente contra bactérias Gram positivas, maiores produtoras de hidrogênio e precursor de metano, do que contra as Gram negativas. Quando a produção de hidrogênio e metano diminui, os cofatores reduzidos durante a fermentação dos carboidratos são oxidados na produção do propionato, aumentando a retenção de energia pelo animal (RUSSELL, 2002).

A monensina também tem sido utilizada em bovinos sob pastejo, mas existem poucos dados sobre a eficiência alimentar nestas condições. Animais a pasto e suplementados ganharam 13,5\% mais peso que animais controle (GOODRICH et al., 1984), sugerindo que as bactérias ruminais de animais que recebem forragem podem ser mais sensíveis ao ionóforo, que aquelas de animais que recebem dieta contendo concentrado.

Culturas microbianas vivas e seus extratos, também têm sido pesquisadas e a ação desses microrganismos parece se concentrar na elevação do consumo, provocado por elevação na taxa de degradação da fibra e no fluxo de nitrogênio absorvível. Há aumento no número de bactérias anaeróbicas, pois aumentam o número das bactérias que utilizam lactato. Também foi observado estabilidade do ambiente ruminal, reduzindo-se as variações diurnas de $\mathrm{pH}$, amônia e ácidos graxos voláteis (JOUANY; MATHIEU; SENAUD, 1998; MORAIS et al., 2011).

Segundo Callaway e Martin (1997), o efeito mais comum da suplementação de levedura é o aumento no número de bactérias do rúmen, especialmente bactérias celulolíticas. Alguns tipos de bactérias apresentam melhor desempenho na presença de leveduras, e alguns fatores relacionados com essa resposta são: fornecimento de fatores de crescimento - vitaminas (complexo B, ácido para-amino benzóico etc...), ácidos dicarboxílicos (fumarato, malato etc...); remoção de oxigênio por Saccharomyces; efeito tampão (bactérias celulolíticas preferem $\mathrm{pH}>6$ ) e redução do número de protozoários.

Assim, objetivou-se avaliar o efeito do ionóforo e do probiótico (sacharomyces cerevisae + selênio 
+ cromo) em dietas ricas em volumoso sobre a digestibilidade total dos nutrientes e degradabilidade in situ da matéria seca, proteína bruta e fibra em detergente neutro em bubalinos e bovinos.

\section{Material e Métodos}

O experimento foi conduzido no setor de Bovinocultura de Corte da Fazenda Experimental de Iguatemi (FEI). As análises químicas foram realizadas no Laboratório de Análises de Alimentos e Nutrição Animal, pertencente ao Departamento de Zootecnia da Universidade Estadual de Maringá.

Foram utilizados, três búfalos, castrados, da raça Murrah com peso corporal médio de $520 \pm 30 \mathrm{~kg}$ e três bovinos, castrados, da raça Holandesa, com peso corporal médio de $480 \pm 182 \mathrm{~kg}$ portadores de cânulas ruminais. Os animais foram mantidos em baias individuais cobertas, com piso de concreto, providas de comedouro e bebedouro.

Os alimentos utilizados para compor a ração basal do experimento foram farelo de soja e grão de milho moído. O volumoso utilizado foi o feno de Tifton 85. As três dietas utilizadas no experimento foram caracterizadas pela presença ou ausência de aditivos, sendo dietas controle, com ionóforo e com probiótico (Tabela 1).

A dieta controle apresentou uma relação de 80:20\% volumoso:concentrado e foi balanceada de acordo com NRC (2001), de forma a apresentar $11,0 \%$ de proteína bruta e $68,0 \%$ de nutrientes digestíveis totais (Tabela 1 ).

O percentual de farelo de soja na ração total foi de $8,0 \%$, de milho foi de $11,0 \%$ e de feno de tifton 85 de $80 \%$, sendo que foi deixado $1 \%$ da ração total para suplementação de sal mineral.

Tabela 1. Composição química dos alimentos, dieta experimental e composição percentual da dieta (\% na MS $)^{1}$.

\begin{tabular}{|c|c|c|c|c|c|c|c|c|}
\hline Alimentos & $\% \mathrm{MS}$ & $\% \mathrm{MO}$ & $\% \mathrm{~PB}$ & $\%$ FDN & $\% \mathrm{FDA}$ & $\% \mathrm{EE}$ & $\mathrm{AM} \%$ & CIA \% \\
\hline Farelo de soja & 89,37 & 94,48 & 47,43 & 14,85 & 7,75 & 1,65 & 13,11 & 0,10 \\
\hline Milho moído & 87,70 & 94,75 & 10,01 & 9,40 & 6,72 & 3,24 & 75,20 & 0,02 \\
\hline Feno de Tifton 85 & 95,05 & 91,11 & 6,60 & 79,81 & 39,98 & 1,56 & 1,84 & 0,91 \\
\hline *ionóforo & 90,33 & 84,24 & 11,88 & 17,35 & 11,03 & 3,79 & 34,50 & - \\
\hline *probiótico & 92,39 & 85,72 & 38,57 & 2,79 & 1,2 & 3,43 & 3,91 & - \\
\hline Dieta $80: 20$ & 93,84 & 91,01 & 10,18 & 66,07 & 33,35 & 1,74 & 10,79 & 0,85 \\
\hline \multicolumn{9}{|c|}{ Composição percentual da dieta experimental ${ }^{2}$} \\
\hline Alimentos & & & & \multicolumn{5}{|c|}{ percentagem } \\
\hline Farelo de soja & & & & \multicolumn{5}{|c|}{8,0} \\
\hline Milho moído & & & & \multicolumn{5}{|c|}{11,0} \\
\hline Feno de Tifton 85 & & & & \multicolumn{5}{|c|}{80,0} \\
\hline Sal mineral & & & & \multicolumn{5}{|c|}{1,0} \\
\hline
\end{tabular}

${ }^{1}$ MS: matéria seca, MO: matéria orgânica, PB: proteína bruta, FDN: fibra em detergente neutro, FDA: fibra em detergente ácido, EE: extrato etéreo, AM: amido. *ionóforo (monensina sódica - Rumensin ${ }^{\circledR}$ ) e probiótico (levedura + selênio + cromo - Beef $\left.\operatorname{sacc}^{\circledR}\right) .{ }^{2}$ Foi adicionado $2 \mathrm{~g}$ ionóforo $\left(10 \%\right.$ monensina sódica - Rumensin $\left.{ }^{\circledR}\right)$ e adicionado $5 \mathrm{~g}$ do probiótico (levedura $+50 \mathrm{mg}$ selênio $+50 \mathrm{mg}$ cromo - beef $\left.-\operatorname{sacc}^{\circledR}\right)$, perfazendo 3 dietas experimentais: controle, ionóforo e probiótico.

Fonte: Elaboração dos autores.

Os aditivos empregados foram ionóforo $(10 \%$ monensina sódica - rumensin $\left.^{\circledR}\right)$ e probiótico contendo levedura (Saccharomyces cerevisae $510^{6}$ $\mathrm{ufc} / \mathrm{g}+$ Selênio $50 \mathrm{mg}+$ Cromo $300 \mathrm{mg}$ ) - beef $\operatorname{sacc}^{\circledR}$.
A alimentação foi fornecida aos animais duas vezes ao dia, em duas porções iguais, pela manhã (8h) e à tarde (16h), sendo o volumoso e o concentrado misturados no cocho. $\mathrm{O}$ feno de Tifton 85 foi triturado em tamanho de aproximadamente 3 $\mathrm{cm}$ com auxílio de picadeira de forragens. 
Os aditivos foram adicionados diretamente no cocho dos animais duas vezes ao dia (manhã $-8 \mathrm{~h}$ e à tarde $-16 \mathrm{~h})$. A dosagem recomendada pelo fabricante foi de $2 \mathrm{~g} /$ animal/dia de ionóforo e $5 \mathrm{~g} /$ animal/dia de probiótico. A dosagem dos aditivos foi dividida em duas vezes ao dia, metade pela manhã ( $1 \mathrm{~g}$ de ionóforo e 2,5 $\mathrm{g}$ de probiótico), sendo a outra metade fornecida no período da tarde. O mesmo procedimento no fornecimento da dieta e aditivos foi mantido para o ensaio in situ.

A estimativa do peso corporal dos animais foi obtida por meio de medição do perímetro torácico no final de cada período de adaptação e no final de cada período de coleta.

Foi conduzido simultaneamente ao ensaio de digestão com bovinos, um ensaio de degradabilidade ruminal em búfalos e bovinos, onde o feno de Tifton 85 foi incubado em sacos de náilon.

Os animais receberam diariamente sal mineral na dieta, obtido da mistura 1:1 de sal comum com um suplemento comercial contendo na sua composição, por $\mathrm{kg}$ do produto, $65,0 \mathrm{~g}$ de fósforo, $130,0 \mathrm{~g}$ de cálcio 5,0 g de magnésio, 13,0 g de enxofre, $700 \mathrm{mg}$ de ferro, $850 \mathrm{mg}$ de cobre, $1000 \mathrm{mg}$ de manganês, $120 \mathrm{~g}$ de iodo e $80 \mathrm{~g}$ de cobalto.

O fornecimento das dietas foi restrito a $2 \%$ do peso corporal para diminuir os efeitos do consumo sobre os coeficientes de digestão.

Cada período experimental (3) teve duração de 21 dias, sendo 14 dias de adaptação e sete dias de coleta. Durante o período de coleta, foram amostradas $100 \mathrm{~g}$ de fezes diretamente do reto, com intervalo de $12 \mathrm{~h}$ e um incremento de $2 \mathrm{~h}$ entre dias consecutivos, num total de 12 amostras por animal. As amostras eram armazenadas em sacos plásticos, devidamente etiquetadas, e congeladas $\left(-20^{\circ} \mathrm{C}\right)$.

Após o período de coleta, as amostras de alimento e fezes foram secas em estufa a $55^{\circ} \mathrm{C}$ por 72 horas, moídas em moinhos contendo peneira com crivo de $1 \mathrm{~mm}$, individualmente e misturadas em quantidades iguais, com base no peso seco, para formar amostras compostas de fezes/animal/dieta.
A degradabilidade ruminal da matéria seca, proteína bruta e fibra em detergente neutro do feno de Tifton 85 foram estimadas pelo método in situ.

O volumoso foi moído em peneira com crivos de $5 \mathrm{~mm}$, depois incubado em sacos de náilon, com dimensões de $10 \times 17 \mathrm{~cm}$ e com diâmetro dos poros de 53 micra. Em cada saco foi pesado $6 \mathrm{~g}$ de feno de tifton 85 e para cada horário existia uma triplicata. Os sacos foram presos a uma barra cilíndrica de ferro inoxidável, com peso de aproximadamente 600 gramas e este foi suspenso por uma corrente de 50 centímetros de comprimento, na cânula ruminal, durante o período de incubação.

Os tempos de incubação ruminal foram de 6,12 , 24, 48, 72 e 96 h, sendo que, a introdução dos sacos foi realizada em duas etapas para permitir que todos tivessem as mesmas condições de fermentação. Após a retirada do rúmen, os sacos foram submersos em água fria, para que a atividade microbiana cessasse. Em seguida foram congelados e posteriormente lavados em máquina de lavar automática (cinco ciclos por $10 \mathrm{~min}$ ). Após a lavagem os sacos de degradabilidade foram pré-secos em estufa com ventilação forçada a $55^{\circ} \mathrm{C}$ por $72 \mathrm{~h}$, e em seguida pesados e os resíduos moídos em peneira com crivos de $1 \mathrm{~mm}$. Foram realizadas análises de matéria seca, proteína bruta e fibra em detergente neutro.

Para determinar a fração solúvel estimou-se o tempo zero (0) h, através de imersão em banhomaria a $39^{\circ} \mathrm{C}$, durante 30 minutos, conforme técnica utilizada por Nocek (1988).

Os dados sobre o desaparecimento da matéria seca, proteína bruta e fibra em detergente neutro foram ajustados por regressão não-linear. Para calcular a degradabilidade potencial (p) dos alimentos utilizou-se o modelo proposto por Mehrez

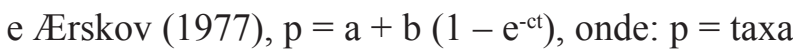
de degradação potencial no tempo t; $a=$ intercepto representando a porção prontamente solúvel no rúmen; $\mathrm{b}=$ fração insolúvel, mas potencialmente degradável; $\mathrm{c}=$ taxa constante de degradabilidade da fração $b ; t=$ tempo de incubação; 
Os parâmetros não-lineares $\mathrm{a}, \mathrm{b}$ e c foram estimados pelos procedimentos iterativos de quadrados mínimos. A degradabilidade efetiva (DE) foi calculada segundo o modelo matemático proposto por Orskov e McDonald (1979), DE = a + $\left(\left(b^{*} \mathrm{c}\right) /(\mathrm{c}+\mathrm{k})\right)$, onde: $\mathrm{k}$ é a taxa estimada de sólidos no rúmen; sendo que os demais parâmetros foram descritos na equação anterior.

A degradabilidade efetiva da matéria seca e demais nutrientes foi estimada para o volumoso, para as taxas de passagem de sólidos de $2 \% / \mathrm{h}, 5 \% / \mathrm{h}$ e $8 \% / h$ que são atribuídas, respectivamente, ao teor baixo, médio e alto de ingestão alimentar (AFRC, 1993).

Para determinação dos fluxos diários de matéria seca nas fezes foi utilizado como indicador interno a cinza insolúvel em ácido (CIA). A determinação da CIA seguiu as recomendações descritas por Van Keulen e Young (1977).

Os coeficientes de digestibilidade aparente total da matéria seca (MS), matéria orgânica (MO), proteína bruta $(\mathrm{PB})$, fibra em detergente neutro (FDN), fibra em detergente ácido (FDA), extrato etéreo (EE), e amido (AM) foram calculados de acordo com as fórmulas descritas por Coelho da Silva e Leão (1979).

As determinações de MS, MO, PB e EE foram realizadas de acordo com as metodologias descritas por Silva e Queiroz (2002). A determinação de FDN e FDA foi conduzida de acordo com Van Soest, Robertson e Lewis (1991). O teor de amido das amostras foi analisado pelo método de Poore et al. (1989) adaptado por Pereira e Rossi (1995).

Foi utilizado delineamento experimental de 2 quadrados latinos $3 \times 3$, em arranjo fatorial $3 \times$ 2 correspondendo as dietas: controle, ionóforo e probiótico; com duas espécies: bubalina e bovina; para comparar a digestão dos nutrientes. As análises estatísticas das variáveis estudadas foram interpretadas no Sistema de Análises Estatísticas e Genéticas (SAEG) por meio de análise de variância (UFV, 1998).
Quando a interação espécie $\mathrm{x}$ dieta foi significativa procedeu-se à análise dos efeitos das dietas dentro de cada espécie (UFV, 1998).

Para a degradabilidade in situ foi utilizado um delineamento experimental em 2 quadrados latinos $3 \times 3$, em arranjo fatorial $3 \times 2$ correspondendo a as dietas: controle, ionóforo e probiótico; e duas espécies (bubalina e bovina), os resultados obtidos para os parâmetros a, b, c, degradabilidade potencial, degradabilidade efetiva com taxa de passagem de $2 \%, 5 \%$ e $8 \% / \mathrm{h}$, das diferentes espécies foram submetidos as análises de variância utilizando o Sistema de Analise Estatística e Genética (SAEG) e comparados utilizando-se o teste de média Tukey ao nível de significância de $5 \%$.

\section{Resultados e Discussão}

Não houve influencia das dietas experimentais (controle, ionóforo e levedura) sobre o consumo médio de MS, PB, FDN, EE e AM em kg/dia e \% PC ( $\mathrm{P}>0,05)$, assim como, não houve diferença entre espécies (bovinos e bubalinos) exceto para o consumo de MO e FDA em \% PC (Tabela 2).

O consumo médio de MS foi semelhante ao preestabelecido para o presente estudo ( $2 \%$ PC). Deste modo, os efeitos do consumo sobre os coeficientes de digestão foram reduzidos, para favorecer a comparação dos resultados observados.

$\mathrm{O}$ consumo de MO e FDA expresso em \% do PC para as espécies estudadas, foi maior $(\mathrm{P}<0,05)$ para a espécie bubalina, embora a diferença fosse de baixa relevância biológica.

Não houve interação $(\mathrm{P}>0,05)$ entre dietas (controle, ionóforo e probiótico) e espécie animal para os coeficientes de digestibilidade da proteína bruta, fibra em detergente ácido e amido. Porém, houve efeito $(\mathrm{P}<0,05)$ de dieta sobre a digestibilidade aparente da PB e FDA, e efeito $(\mathrm{P}<0,05)$ de espécie sobre os coeficientes de digestibilidade aparente da PB, FDA e amido (Tabela 3). 
Tabela 2. Consumo médio diário de matéria seca e nutrientes de dietas contendo ou não ionóforo e probiótico em bovinos e bubalinos.

\begin{tabular}{|c|c|c|c|c|c|c|}
\hline \multirow[t]{2}{*}{ Variáveis } & \multicolumn{3}{|c|}{ Dietas Experimentais } & \multicolumn{2}{|c|}{ Espécies } & \multirow[t]{2}{*}{ DP } \\
\hline & Controle & Ionóforo & Probiótico & Bubalino & Bovino & \\
\hline \multicolumn{7}{|l|}{ Matéria Seca } \\
\hline $\mathrm{kg} / \mathrm{dia}$ & 9,97 & 9,82 & 9,97 & 10,38 & 9,46 & $9,92 \pm 2,21$ \\
\hline \% Peso corporal & 1,99 & 1,97 & 1,99 & 1,99 & 1,97 & $1,98 \pm 0,030$ \\
\hline \multicolumn{7}{|l|}{ Matéria orgânica } \\
\hline $\mathrm{kg} / \mathrm{dia}$ & 9,06 & 8,93 & 9,06 & 9,43 & 8,60 & $9,02 \pm 2,01$ \\
\hline$\%$ Peso corporal & 1,81 & 1,81 & 1,81 & $1,82 \mathrm{a}$ & $1,81 \mathrm{~b}$ & $1,81 \pm 0,009$ \\
\hline \multicolumn{7}{|l|}{ Proteína Bruta } \\
\hline $\mathrm{kg} / \mathrm{dia}$ & 1,00 & 0,86 & 1,00 & 1,03 & 0,88 & $0,96 \pm 0,25$ \\
\hline$\%$ Peso corporal & 0,20 & 0,20 & 0,20 & 0,20 & 0,20 & $0,20 \pm 0,001$ \\
\hline \multicolumn{7}{|c|}{ Fibra em detergente neutro } \\
\hline $\mathrm{kg} / \mathrm{dia}$ & 6,61 & 6,51 & 6,61 & 6,88 & 6,27 & $6,57 \pm 1,47$ \\
\hline$\%$ Peso corporal & 1,32 & 1,32 & 1,32 & 1,33 & 1,32 & $1,30 \pm 0,150$ \\
\hline \multicolumn{7}{|c|}{ Fibra em detergente ácido } \\
\hline $\mathrm{kg} / \mathrm{dia}$ & 3,33 & 3,28 & 3,33 & 3,47 & 3,16 & $3,31 \pm 0,74$ \\
\hline$\%$ Peso corporal & 0,66 & 0,66 & 0,66 & $0,67 \mathrm{a}$ & $0,66 \mathrm{~b}$ & $0,66 \pm 0,003$ \\
\hline \multicolumn{7}{|l|}{ Extrato etéreo } \\
\hline $\mathrm{kg} / \mathrm{dia}$ & 0,17 & 0,17 & 0,17 & 0,18 & 0,16 & $0,17 \pm 0,04$ \\
\hline$\%$ Peso corporal & 0,03 & 0,03 & 0,03 & 0,03 & 0,03 & $0,03 \pm 0,004$ \\
\hline \multicolumn{7}{|l|}{ Amido } \\
\hline $\mathrm{kg} / \mathrm{dia}$ & 0,21 & 0,16 & 0,22 & 0,20 & 0,19 & $0,20 \pm 0,05$ \\
\hline$\%$ Peso corporal & 0,40 & 0,40 & 0,40 & 0,40 & 0,40 & $0,40 \pm 0,005$ \\
\hline
\end{tabular}

Médias nas linhas, seguidas por letras iguais não diferem $(\mathrm{P}<0,05)$ pelo teste de Tukey; DP: Desvio padrão da Média.

Fonte: Elaboração dos autores.

Tabela 3. Coeficientes de digestibilidade aparente total da proteína bruta (PB), da fibra em detergente ácido (FDA), e do amido (AM) em dietas contendo ou não ionóforo e probiótico em bovinos e bubalinos.

\begin{tabular}{|c|c|c|c|c|c|c|}
\hline \multirow{2}{*}{ Nutrientes } & \multicolumn{3}{|c|}{ Dietas experimentais (\% MS) } & \multicolumn{2}{|c|}{ Espécies } & \multirow[t]{2}{*}{ DP } \\
\hline & Controle & Ionóforo & Probiótico & Bubalino & Bovino & \\
\hline PB & $56,8 \mathrm{~B}$ & $61,4 \mathrm{~A}$ & $57,3 \mathrm{~B}$ & 59,9 a & $53,7 \mathrm{~b}$ & $57,8 \pm 2,97$ \\
\hline FDA & $43,8 \mathrm{~B}$ & $46,6 \mathrm{~A}$ & $47,8 \mathrm{~A}$ & $49,2 \mathrm{a}$ & $43,0 \mathrm{~b}$ & $46,1 \pm 2,63$ \\
\hline $\mathrm{AM}$ & 82,3 & 82,9 & 82,6 & $81,2 \mathrm{~b}$ & $84,0 \mathrm{a}$ & $82,6 \pm 1,01$ \\
\hline
\end{tabular}

Médias na mesma linha seguidas com letras maiúsculas iguais não diferem entre dietas pelo teste de Tukey $(\mathrm{P}<0,05)$. Médias na mesma linha seguidas com letras minúsculas iguais, não diferem entre espécie animal pelo teste de Tukey $(\mathrm{P}<0,05)$. DP: Desviopadrão.

Fonte: Elaboração dos autores.

O maior coeficiente de digestibilidade da PB foi obtido para a dieta contendo ionóforo $(61,4 \%)$, seguido da dieta com probiótico $(57,3 \%)$ e dieta controle $(56,8 \%)$, as quais não diferiram entre si. A maior digestibilidade aparente da PB em dieta com ionóforo também foram observadas por Galloway et al., 1993.
Segundo Rodrigues et al. (2001), o efeito da monensina em aumentar a digestibilidade da PB independe do teor de fibra na dieta, embora a literatura demonstre maior efeito do produto em dietas predominantemente concentradas. 
$\mathrm{O}$ aumento da digestibilidade da FDA com a adição de ionóforo foi semelhante aos observados por Zeoula et al. (2008) testando dietas com 50:50 volumoso:concentrado onde constataram menor valor para dieta contendo ionóforo $(43,9 \%)$ e maior valor para a dieta contendo probiótico $(45,5 \%)$.

Pomar et al. (1989) observaram que a monensina diminuiu a digestibilidade da FDN e FDA em dietas com $75 \%$ e $90 \%$ de concentrado, mas aumentou a digestibilidade destas frações fibrosas em dietas com 70\% de volumoso. Todavia, Zinn, Plascencia e Barajas (1994) não demonstraram efeitos dos ionóforos sobre a digestibilidade da fibra, independente do teor de fibra da dieta. O efeito dos ionóforos sobre a digestibilidade da fibra tem sido comumente explicado na literatura como sendo decorrente do aumento do tempo de retenção da MS no rúmen, devido ao menor consumo voluntário de alimentos (ROGERS; DAVIS, 1982), melhora nas condições ruminais (BRANINE; GALYEAN, 1990) ou aumento no estímulo à ruminação (KNOWLTON; ALLEN; ERIKSON, 1996).

Borges (2006), avaliaram os efeitos da terramicina e monensina sódica sobre a digestão de nutrientes em bovinos alimentados com dietas contendo alto nível de concentrado (60\%), e observaram que não houve diferença entre a dieta controle e com monensina sódica sobre a digestão da fibra em bovinos.

Não houve diferença entre dietas para a digestibilidade aparente do amido, sendo o valor médio da digestibilidade do amido de 82,6\% ( $\mathrm{P}>0,05$, Tabela 3).

Com relação às espécies, o maior coeficiente de digestibilidade da PB foi observado para os bubalinos com $59,9 \%$, sendo superior aos $53,7 \%$ verificado para os bovinos. Tem sido relatado pequena vantagem na digestibilidade da proteína bruta em búfalos em relação aos bovinos, assumindo-se que há uma tendência dos búfalos perderem menos nitrogênio pela urina e pelas fezes, aproveitando melhor o nitrogênio dos alimentos (EZEQUIEL, 1987) e apresentarem maior capacidade de reciclagem de $\mathrm{N}$ (ABDULLAH et al., 1992).
O coeficiente de digestibilidade aparente dos nutrientes e características ruminais de dietas com diferentes níveis de concentrado (23\%, 43\% e 63\% na MS) para bubalinos e bovinos foi avaliados por Maeda et al. (2007), os quais não encontraram diferença $(\mathrm{P}>0,05)$ na digestibilidade total da $\mathrm{PB}$ em bubalinos (62\%) e bovinos (64,5\%). Entretanto, no presente trabalho a diferença para o coeficiente de digestibilidade da PB foi maior para a espécie bubalina $(59,9 \%, \mathrm{P}<0,05)$ em relação aos bovinos $(53,7 \%)$.

Houve diferença entre as espécies estudadas $(\mathrm{P}<0,05)$ para a digestibilidade da FDA, sendo que a espécie bubalina apresentou maior valor $(49,2 \%)$ em relação à espécie bovina (43,0\%). Zeoula et al. (2008), utilizaram uma ração com proporção volumoso:concentrado de 50:50 e com teor de 17,84\% de FDA nas rações e observaram que a digestibilidade média da FDA para ambas espécies foi de 43,9\%. Todavia, no presente estudo com relação volumoso:concentrado de 80:20 e com teor de 33,35\% de FDA na ração total, o coeficiente de digestibilidade total para a FDA foi superior como mostrado acima.

Diferenças entre búfalos e zebus, e, entre zebuínos e taurinos são verificadas quando dietas de qualidade inferior são oferecidas, pois com dietas de melhor qualidade não se observou diferença entre as espécies (KENNEDY, 1982). Segundo Batista, Autrey e Thiesenhausen (1982), os búfalos têm maior capacidade de digerir rações com maiores teores de fibra e menores de proteína do que os bovinos. De acordo com Pradhan, Bhatia e Sangwan (1997), os bubalinos apresentaram maiores coeficientes de digestão do que os bovinos, quando a forragem era de baixa qualidade. Alguns pesquisadores atribuem vantagens aos búfalos na utilização de alimentos fibrosos, devido ao menor movimento ruminal em búfalos do que em bovinos, bem como maior tempo de exposição à ação dos microrganismos (SHARMA, 1988; BARTOCCI, et al., 1997). 
Entretanto, em relação às espécies estudadas, houve efeito $(\mathrm{P}<0,05)$ para o coeficiente de digestibilidade do AM, sendo que os bovinos apresentaram 84,0\% de digestão total do amido, superior aos $81,2 \%$ verificados para os búfalos. Da mesma forma, Zeoula et al. (2008) avaliaram dietas com relação volumoso:concentrado de 50:50\% e portanto com maior teor de amido, e a espécie bovina mostrou-se também superior à espécie bubalina, para a digestibilidade do amido $(88,67 \%$ vs $86,02 \%$ ).

Em estudo testando diferentes teores de concentrado $(23 \%, 43 \%$ e $63 \%)$ em bubalinos e bovinos Maeda et al. (2007) verificaram maiores valores de digestibilidade do amido para os bovinos $(95,7 \%)$, em relação aos búfalos $(85,8 \%)$. Para os referidos pesquisadores a menor digestibilidade do amido em bubalinos seria consequência de um período de adaptação insuficiente à dieta com teores mais elevados de concentrado (30 dias) gerando menor consumo de matéria seca pelos búfalos em relação aos bovinos.

Houve efeito de interação $(\mathrm{P}<0,05)$ entre as dietas contendo ou não aditivo e espécies (bubalina e bovina), sobre os coeficientes de digestibilidade da MS, MO, FDN e do EE (Tabela 4).

Tabela 4. Coeficientes de digestibilidade aparente total da matéria seca (MS), matéria orgânica (MO), fibra em detergente neutro (FDN) e extrato etéreo (EE) em dietas contendo ou não ionóforo e probiótico em bovinos e bubalinos.

\begin{tabular}{lllllllll}
\hline \multirow{2}{*}{ Nutrientes } & \multicolumn{3}{c}{ Bubalino } & & \multicolumn{3}{c}{ Bovino } & \multirow{2}{*}{ DP } \\
\cline { 2 - 4 } & Controle & Ionóforo & Probiótico & & Controle & Ionóforo & Probiótico & \\
\hline MS & $58,2 \mathrm{Ba}$ & $59,1 \mathrm{Ba}$ & $62,5 \mathrm{Aa}$ & & $57,0 \mathrm{Ab}$ & $54,8 \mathrm{Bb}$ & $56,4 \mathrm{Ab}$ & $58,0 \pm 2,67$ \\
MO & $60,4 \mathrm{Ba}$ & $60,6 \mathrm{Ba}$ & $64,3 \mathrm{Aa}$ & & $60,2 \mathrm{Aa}$ & $56,8 \mathrm{Bb}$ & $59,0 \mathrm{Ab}$ & $60,2 \pm 2,44$ \\
FDN & $52,5 \mathrm{Ba}$ & $53,3 \mathrm{Ba}$ & $56,7 \mathrm{Aa}$ & & $51,4 \mathrm{a}$ & $49,1 \mathrm{~b}$ & $50,1 \mathrm{~b}$ & $52,2 \pm 2,71$ \\
$\mathrm{EE}$ & $67,2 \mathrm{a}$ & $68,1 \mathrm{a}$ & $69,2 \mathrm{a}$ & & $67,4 \mathrm{Ba}$ & $69,7 \mathrm{Aa}$ & $66,9 \mathrm{Bb}$ & $68,1 \pm 1,13$ \\
\hline
\end{tabular}

Letras maiúsculas comparam médias nas linhas entre dietas experimentais (controle, ionóforo - Monensina sódica e probiótico Sacharomyces cerevisae)) dentro da espécie (bubalino e bovino), e letras minúsculas comparam médias nas linhas entre as espécies dentro das dietas experimentais. Médias seguidas com letras iguais não diferem pelo teste de Tukey ( $<<0,05)$. DP: desvio-padrão. Fonte: Elaboração dos autores.

Em relação às espécies animais, os bubalinos apresentaram maiores coeficientes de digestibilidade da MS em relação aos bovinos $(\mathrm{P}<0,05)$.

Para as digestibilidades da MO e FDN, as três dietas testadas em búfalos e a dieta controle em bovinos foram semelhantes entre si $(\mathrm{P}>0,05)$ e superiores às dietas com ionóforo e probiótico em bovinos ( $\mathrm{P}<0,05$; Tabela 4$)$.

Para a digestibilidade do EE houve semelhança entre as dietas testadas em búfalos e bovinos, exceto para a dieta contendo probiótico em bovinos que apresentou valor inferior às demais $(\mathrm{P}<0,05)$.

Em relação às dietas dentro de cada espécie animal, tem-se que, para bubalinos, a dieta contendo probiótico apresentou valores superiores de digestibilidade da MS, MO e FDN em relação às dietas controle e ionóforo $(\mathrm{P}<0,05)$.

Não houve diferença entre os valores de digestibilidade do $\mathrm{EE}$ entre as dietas em bubalinos ( $\mathrm{P}>0,05$; Tabela 4).

Observando-se as diferentes dietas em bovinos tem-se que a dieta contendo probiótico não diferiu da dieta controle para a digestibilidade da MS e $\mathrm{MO}$ e apresentaram-se superiores à dieta contendo ionóforo $(\mathrm{P}<0,05)$. Lewis et al. (1996), observaram melhora de 5,0\% na digestibilidade da MS, quando forneceram enzimas a novilhos recebendo dieta com 70\% de volumoso. Todavia, Queiroz et al. (2004), utilizaram um produto a base de enzima + levedura em dietas de bovinos com a relação volumoso:concentrado de 65:35 e não observaram 
diferença para o coeficiente de digestibilidade aparente da MS.

Em estudo realizado por Galloway et al. (1993), com novilhos holandeses alimentados com uma dieta volumosa de baixa qualidade, suplementada com monensina, ocorreu aumento da digestibilidade da matéria orgânica. Entretanto, no presente trabalho, os animais receberam também uma dieta de baixa qualidade com proporção de volumoso:concentrado, de 80:20 e, no entanto, a dieta contendo ionóforo fornecida aos bovinos apresentou baixa digestibilidade da $\mathrm{MO}$, em relação à dieta controle.

Não houve diferença entre dietas na digestibilidade da FDN em bovinos $(\mathrm{P}>0,05)$ a qual apresentou valor médio de 50,2\%. Pereira et al. (2001), em estudo sobre a digestibilidade em novilhos com dietas à base de cana-de-açúcar + levedura, observaram valor inferior ao do presente estudo, de 31,6\% para a digestibilidade da FDN, e concluíram que o uso de leveduras não influenciou a digestibilidade da FDN.

Em bovinos, diferentemente da digestibilidade da MS, a digestibilidade do EE da dieta contendo ionóforo foi superior às dietas controle e probiótico e essas duas não diferiram entre si (Tabela 4).

Como observado no presente trabalho, Johnson Jr. et al. (1988) relataram aumento da digestibilidade dos lipídios com o uso de ionóforos em dietas suplementadas com gordura, para novilhos. Entretanto, Rodrigues et al. (2001), utilizando monensina em dietas de ovinos alimentados com a proporção de 75:25\% de volumoso:concentrado, observaram $64,8 \%$ de digestão total do EE, valor inferior ao observado no presente estudo $(69,08 \%)$, onde bovinos receberam dieta com a proporção de 80:20\% de volumoso:concentrado + ionóforo.
A melhor digestibilidade da FDN para espécie bubalina foi observada para a dieta contendo probiótico $(56,7 \%)$, em relação às rações com ionóforo e controle, cujos valores, respectivos, de $53,3 \%$ e $52,5 \%$ foram semelhantes.

Para o coeficiente de digestibilidade do EE na espécie bubalina, as dietas controle, com adição de ionóforo e probiótico não diferiram $(\mathrm{P}>0,05)$. A presença de probiótico ou de ionóforo às dietas com a proporção 80:20\% de volumoso:concentrado verificou-se digestibilidade total da FDN, superior $(\mathrm{P}<0,05)$ para a espécie bubalina em relação a bovina, e para as dietas controle dentro de espécies não houve diferença $(\mathrm{P}>0,05)$, apesar de maior valor numérico ser verificado para a espécie bubalina. Esses resultados ressaltam que os búfalos são eficientes na habilidade de digerir a fibra em dietas de qualidade inferior quando comparados aos Bos taurus, o que corroboram com os resultados observados por diversos pesquisadores (BHATIA et al., 1995; RESENDE; QUEIROZ; FONTES, 1995; HUSSAIN; CHEEKE, 1996; SOUZA et al., 2000).

$\mathrm{Se}$ for considerado o coeficiente de digestibilidade do EE entre as espécies estudadas, a dieta com probiótico foi superior $(\mathrm{P}<0,05)$ para espécie bubalina $(69,7 \%)$, em relação à espécie bovina $(66,9 \%)$.

Houve efeito da interação $(\mathrm{P}<0,05)$ entre dietas experimentais (com ou sem aditivos) e espécie animal sobre os parâmetros "a" e "b" da MS, PB e FDN, e DP e DE $(2 \%, 5 \%$ e $8 \% / \mathrm{h})$ da PB (Tabela 5$)$.

Os valores médios observados da fração solúvel "a” da MS, PB e FDN não serão discutidos, pois suas determinações ocorreram fora do ambiente ruminal dos animais e desta forma não tiveram contato com a microbiota ruminal que estava recebendo como substratos as dietas experimentais com ou sem aditivos. 
Tabela 5. Frações solúvel (a) e potencialmente degradável (b), taxa de degradação (c), da matéria seca (MS), proteína bruta (PB) e fibra em detergente neutro (FDN) e degradabilidade potencial (DP) e degradabilidade efetiva (DE) da PB de feno de Tifton 85 para as taxas de passagem de $2 \% / \mathrm{h}, 5 \%$ e $8 \% / \mathrm{h}$.

\begin{tabular}{|c|c|c|c|c|c|c|c|c|}
\hline \multirow{2}{*}{\multicolumn{2}{|c|}{ Variáveis }} & \multicolumn{3}{|c|}{ Bubalino } & \multicolumn{3}{|c|}{ Bovino } & \multirow[b]{2}{*}{$\mathrm{CV}$} \\
\hline & & Controle & Ionóforo & Probiótico & Controle & Ionóforo & Probiótico & \\
\hline \multirow{3}{*}{ MS } & $\mathrm{a}(\%)$ & $13,5 \mathrm{ABa}$ & $13,0 \mathrm{Ba}$ & $14,8 \mathrm{Aa}$ & $14,6 \mathrm{Aa}$ & $12,3 \mathrm{Bb}$ & $12,6 \mathrm{Bb}$ & 3,80 \\
\hline & $\mathrm{b}(\%)$ & $47,4 \mathrm{Aa}$ & $47,3 \mathrm{Aa}$ & $40,3 \mathrm{Bb}$ & $35,5 \mathrm{Bb}$ & $41,9 \mathrm{Ab}$ & $38,8 \mathrm{Bb}$ & 6,50 \\
\hline & $\mathrm{c}$ & 0,03 & 0,03 & 0,02 & 0,04 & 0,03 & 0,03 & 29,42 \\
\hline \multirow{7}{*}{ PB } & $\mathrm{a}(\%)$ & $11,4 \mathrm{ABa}$ & $10,2 \mathrm{Bb}$ & $13,9 \mathrm{Aa}$ & $11,3 \mathrm{Aa}$ & $12,7 \mathrm{Aa}$ & $11,8 \mathrm{Ab}$ & 3,27 \\
\hline & $\mathrm{b}(\%)$ & $33,3 \mathrm{Ba}$ & $39,4 \mathrm{Aa}$ & $24,8 \mathrm{Cb}$ & $25,7 \mathrm{Bb}$ & $31,0 \mathrm{~b} \mathrm{Ab}$ & $25,7 \mathrm{Ba}$ & 5,52 \\
\hline & $\mathrm{c}$ & 0,03 & 0,02 & 0,03 & 0,02 & 0,03 & 0,03 & 33,25 \\
\hline & DP & $44,7 \mathrm{Ba}$ & 49,6 Aa & $38,7 \mathrm{Ca}$ & $37,0 \mathrm{Bb}$ & $43,7 \mathrm{Ab}$ & $37,5 \mathrm{Bb}$ & 3,60 \\
\hline & DE $2 \% / h$ & $30,2 \mathrm{a}$ & $29,9 \mathrm{a}$ & $28,9 \mathrm{a}$ & $22,6 \mathrm{Bb}$ & $30,8 \mathrm{Aa}$ & $26,3 \mathrm{ABa}$ & 6,18 \\
\hline & DE $5 \% / h$ & $22,9 \mathrm{a}$ & $21,5 \mathrm{a}$ & $23,5 \mathrm{a}$ & $17,5 \mathrm{Bb}$ & $24,0 \mathrm{Aa}$ & $20,6 \mathrm{Ba}$ & 7,85 \\
\hline & DE $8 \% / h$ & $19,6 \mathrm{a}$ & $18,1 \mathrm{a}$ & $21,0 \mathrm{a}$ & $15,6 \mathrm{Bb}$ & $20,9 \mathrm{Aa}$ & $18,1 \mathrm{ABa}$ & 7,80 \\
\hline \multirow{3}{*}{ FDN } & $\mathrm{a}(\%)$ & $2,7 \mathrm{Cb}$ & $3,4 \mathrm{Ba}$ & $5,2 \mathrm{Aa}$ & $5,2 \mathrm{Aa}$ & $4,4 \mathrm{ABa}$ & $3,1 \mathrm{Bb}$ & 16,01 \\
\hline & $\mathrm{b}(\%)$ & $56,4 \mathrm{Aa}$ & $55,6 \mathrm{Aa}$ & $50,6 \mathrm{Ba}$ & $42,9 \mathrm{Bb}$ & $48,7 \mathrm{Ab}$ & $50,0 \mathrm{Aa}$ & 5,33 \\
\hline & $\mathrm{c}$ & 0,04 & 0,03 & 0,03 & 0,05 & 0,03 & 0,03 & 22,00 \\
\hline
\end{tabular}

Letras maiúsculas comparam médias nas linhas entre dietas experimentais (controle, ionóforo - Monensina sódica e probiótico Sacharomyces cerevisae)) dentro da espécie (bubalino e bovino), e letras minúsculas comparam médias nas linhas entre as espécies dentro das dietas experimentais. Médias na mesma linha, seguida de letras iguais, não diferem pelo teste de Tukey ( $\mathrm{P}<0,05)$.

Fonte: Elaboração dos autores.

A fração "b" com potencial de degradação no rúmen com relação à $\mathrm{MS}, \mathrm{PB}$ e FDN do feno de Tifton 85 , na espécie bubalina foram diminuídas pela presença de probiótico em relação às dietas controle e ionóforo, que não diferiram entre si, com exceção da fração "b" da PB que foi aumentada pela presença de ionóforo em relação as demais dietas. $\mathrm{Da}$ mesma forma, a degradabilidade potencial (DP) da PB para a espécie bubalina foi reduzida pela presença de probiótico $(38,7 \%)$, porém, houve aumento $(\mathrm{P}<0,05)$ para a dieta com ionóforo $(49,6 \%)$. Todavia, a degradabilidade efetiva da PB para as diferentes taxas de passagem de sólido $(2 \% / \mathrm{h}, 5 \% / \mathrm{h}$ e $8 \% / \mathrm{h})$ não diferiu entre a presença ou ausência de aditivos em bubalinos.

Com relação à espécie bovina, a presença do probiótico não alterou a fração com potencial de degradação no rúmen quanto à MS e PB (b) do feno de Tifton 85 , em relação à dieta controle, mas aumentou a fração com potencial de degradação da FDN. A presença de ionóforo aumentou a fração potencialmente degradável (b) da MS e PB em relação à dieta controle. Todavia, não se diferenciou da dieta com probiótico para a FDN (Tabela 5).
A fração "b" da MS, PB e FDN do feno de Tifton 85 foi superior para os búfalos em relação aos bovinos quando alimentados com dieta controle. Entretanto, a presença dos aditivos, ionóforo ou probiótico nas dietas alteraram esses parâmetros. O ionóforo aumentou a fração " $b$ " da MS, PB e FDN na espécie bubalina em relação à bovina e o probiótico aumentou a fração "b" da PB e da FDN para os bovinos em relação aos bubalinos.

Para os valores observados de degradabilidade potencial (DP) da PB na espécie bovina, semelhante aos bubalinos, ocorreu aumento desta fração com a adição de ionóforo em relação às demais dietas. Entretanto, na espécie bovina também se verificou aumento para a degradabilidade efetiva (DE) da PB, para as diferentes taxa de passagem de sólidos com adição de ionóforo em relação à dieta controle.

Este comportamento da presença de ionóforo em aumentar a degradabilidade potencial e efetiva da $\mathrm{PB}$ não concorda com os valores observados para a digestibilidade ruminal, quando os bovinos alimentados com dieta de proporção 
de volumoso:concentrado de 80:20, com adição de ionóforo, apresentaram os menores valores de digestão ruminal da proteína. Deve-se levar em consideração que a degradabilidade in situ da PB mede a digestão e fermentação da $\mathrm{PB}$ e a digestibilidade ruminal da $\mathrm{PB}$ mede digestão e absorção da PB na forma de amônia pela parede ruminal. A degradabilidade potencial (DP) e a degradabilidade efetiva da PB para taxas de passagem de $2 \% / \mathrm{h}, 5 \% / \mathrm{h}$ e $8 \% / \mathrm{h}$ do feno de Tifton 85 foi superior para os bubalinos $(44,7 \%, 30,2 \%, 22,9 \%$ e $19,6 \%$, respectivamente) em relação aos bovinos (37,0\%, 22,6\%, 17,5\% e 15,5\%, respectivamente) quando alimentados com a dieta controle (Tabela 5). Esses resultados discordam daqueles observados por Maeda et al. (2007) que não encontraram diferença entre bubalinos e bovinos e observaram maiores valores para a DP da PB do feno de Tifton 85 , respectivamente, 52,4 e $54,7 \%$ e para a DE da $\mathrm{PB}$, para as taxas de passagem de $2 \% / \mathrm{h}, 5 \% / \mathrm{h}$ e 8\%/h (bubalinos: $49,4 \%, 45,4 \%$ e $42,1 \%$ e bovinos: $51,5 \% 47,4 \%$ e $44,0 \%$ ). As diferenças observadas nos valores de degradabilidade ruminal da PB entre os dois experimentos podem ser devido ao teor de PB do feno de tifton 85 usado pelos referidos pesquisadores, o qual continha teor de $\mathrm{PB}$ de $6,9 \%$ e teor de nitrogênio insolúvel em detergente neutro (NIDA/N total) de 35,3\%. Entretanto, os animais, no presente trabalho, quando alimentados com as dietas com aditivos (ionóforo e probiótico), não foi observada diferença entre as espécies para a DE da PB para as diferentes taxas de passagens $(\mathrm{P}>0,05$, Tabela 5).

Não houve interação $(\mathrm{P}>0,05)$ de espécie e dietas experimentais para a degradabilidade potencial (DP) e efetiva (DE) da matéria seca e da fibra em detergente neutro do feno de Tifton 85 , para as taxas de passagem de $2 \%, 5 \%$ e $8 \% / \mathrm{h}$. Verificou-se efeito $(\mathrm{P}<0,05)$ das dietas e da espécie animal sobre a DP e DE $(2 \%, 5 \%$ e $8 \% / h)$ da MS e FDN (Tabela 6).

A DP da MS foi maior para a dieta com ionóforo em relação à dieta com probiótico, porém, não diferiu em relação à dieta controle. Entretanto, a DE da MS para as taxa de passagem de sólidos de $5 \%$ e $8 \% / h$, foi reduzida com a adição de ionóforo e probiótico em relação à dieta controle.

A DP da FDN do feno de Tifton 85 não diferiu com a presença ou ausência de aditivos. Entretanto, houve redução da DE da FDN para as diferentes taxas de passagem de sólidos nas dietas contendo probiótico e ionóforo ( $\mathrm{P}<0,05$, Tabela 6$)$.

Tabela 6. Taxa de degradabilidade potencial (DP) e degradabilidade efetiva (DE) da matéria seca (MS) e fibra em detergente neutro (FDN) do feno de Tifton 85 para as taxas de passagem de $2 \% / \mathrm{h}, 5 \% \mathrm{~h}$ e $8 \% / \mathrm{h}$.

\begin{tabular}{|c|c|c|c|c|c|c|}
\hline & \multicolumn{3}{|c|}{ Dietas Experimentais (\% MS) } & \multicolumn{2}{|c|}{ Espécies } & \multirow[t]{2}{*}{$\mathrm{CV}$} \\
\hline & Controle & Ionóforo & Probiótico & Bubalino & Bovino & \\
\hline \multicolumn{7}{|l|}{ MS } \\
\hline DP & $55,5 \mathrm{AB}$ & $57,2 \mathrm{~A}$ & $53,2 \mathrm{~B}$ & $58,8 \mathrm{a}$ & $52,0 \mathrm{~b}$ & 4,40 \\
\hline DE $2 \% / h$ & 40,1 & 37,4 & 35,1 & 39,2 & 35,9 & 5,03 \\
\hline DE $5 \% / h$ & $30,8 \mathrm{~A}$ & $27,7 \mathrm{~B}$ & $26,5 \mathrm{~B}$ & 29,3 & 27,4 & 7,32 \\
\hline DE $8 \% / h$ & $26,4 \mathrm{~A}$ & $23,5 \mathrm{~B}$ & $22,8 \mathrm{~B}$ & 25,0 & 23,5 & 7,62 \\
\hline \multicolumn{7}{|l|}{ FDN } \\
\hline DP & 53,6 & 56,15 & 54,4 & $58,0 \mathrm{a}$ & $51,5 \mathrm{~b}$ & 5,13 \\
\hline DE $2 \% / h$ & $36,8 \mathrm{~A}$ & $35,7 \mathrm{AB}$ & $33,4 \mathrm{~B}$ & 36,5 & 34,2 & 5,80 \\
\hline DE $5 \% / h$ & $25,9 \mathrm{~A}$ & $24,0 \mathrm{AB}$ & $22,1 \mathrm{~B}$ & 24,4 & 23,7 & 8,90 \\
\hline DE $8 \% / h$ & $20,5 \mathrm{~A}$ & $18,6 \mathrm{AB}$ & $17,2 \mathrm{~B}$ & 18,9 & 18,7 & 10,41 \\
\hline
\end{tabular}

Letras maiúsculas comparam médias nas linhas entre dietas experimentais (controle, ionóforo - Monensina sódica e probiótico Sacharomyces cerevisae), e letras minúsculas comparam médias nas linhas entre as espécies (bubalino e bovino). Médias seguidas com letras iguais não diferem pelo teste de Tukey $(\mathrm{P}<0,05)$.

Fonte: Elaboração dos autores. 
AmenorDEdaFDN do feno de Tifton 85(Cynodon dactylon) apresentado pela dieta com probiótico não concorda com a maior digestibilidade ruminal da FDN obtido para esta dieta, quando se utilizou uma relação de 80:20 de volumoso:concentrado para o ensaio de digestibilidade total. Como já discutido anteriormente e pelos resultados observados na literatura (NICODEMO, 2001; NEWBOLD, 1997; QUEIROZ, 2004), verifica-se que a presença de leveduras aumenta a digestibilidade principalmente da fração fibrosa. Entretanto, este fato não foi detectado no ensaio in situ. Talvez o próprio método e a equação utilizada para descrever esses parâmetros não tenham sido os mais adequados para representar a degradabilidade ruminal da fibra.

Houve diferença $(\mathrm{P}<0,05)$ na degradabilidade potencial da MS e da FDN para as espécies estudadas, tendo a espécie bubalina apresentado maiores valores. Todavia, quando se levou em consideração a taxa de passagem de sólidos não houve diferença entre as espécies para DE. Esses resultados discordam em parte com aqueles observados por Maeda, Zeoula e Fussiger (2005) que não observaram diferença entre bubalinos e bovinos na DP e na DE da MS, para as diferentes taxas de passagem de sólidos, do feno de Tifton 85. Portanto, no presente trabalho evidenciou-se a maior capacidade de atuação dos microrganismos celulolíticos na habilidade de digestão de fibra, na espécie bubalina, quando foi considerado apenas o tempo de permanência no rúmen.

\section{Conclusão}

A inclusão de ionóforo em dieta com relação volumoso:concentrado de 80:20, propicia melhor aproveitamento da digestão total da $\mathrm{PB}$ para a espécie bubalina. Todavia, a digestão total da fibra, com a inclusão de probiótico à dieta, para os bubalinos, é melhor aproveitada.

A dieta contendo probiótico apresenta maiores coeficientes de digestibilidade da matéria seca e matéria orgânica, em bubalinos e bovinos, indicando bom desempenho em dietas volumosas.

A degradabilidade potencial e efetiva da matéria seca da dieta com probiótico é inferior à dieta com ionóforo, em búfalos, sugerindo que há melhor digestão dos nutrientes no intestino grosso destes animais.

A degradabilidade potencial e efetiva da fibra em detergente neutro e proteína bruta na dieta contendo ionóforo são superiores à dieta contendo probiótico.

Bubalinos apresentam maior capacidade de digestão de matéria seca e fração fibrosa do que bovinos.

\section{Referências}

ABDULLAH, N.; NOLAN, J. V.; MAHYUDDIN, M.; JALALUDIN, S. Digestion and nitrogen conservation in cattle and buffaloes given rice straw with or without molasses. Journal of Agricultural Science, Cambridge, v. 119, n. 2, p. 255-263, 1992.

AGRICULTURALAND FOOD RESEARCH COUNCIL - AFRC. Energy and protein requeriment of ruminants. Wallingford: CAB international, 1993. $159 \mathrm{p}$.

BARTOCCI, S.; AMICI, A.; VERNA, M.; TERRAMOCCIA, S.; MARTILLOTTI, F. Solid and fluid passage rate in buffalo, cattle, and sheep fed diets with different forage to concentrate ratios. Livestock Production Science, London, v. 52, n. 3, p. 201-208, 1997.

BHATIA, S. K.; SANGWAN, D. C.; PRADHAN, K.; SINGH, R.; SAGAR, V. Ruminal degradation of fibrous components of various feeds in cattle and buffalo. Indian Journal of Animal Sciences, New Delhi, v. 65, n. 2, p. 208-212, 1995.

BORGES, L. F. de O. Efeito da terramicina ou Monesina sódica sobre a fermentação ruminal e a digestão total em bovinos. 2006. Dissertação (Mestrado em Zootecnia) - Universidade de São Paulo, Pirassununga.

BRANINE, M. E.; GALYEAN, M. L. Influence of grain and monensina supplememntation on ruminal fermentation, intake, digesta kinetics and incidence and severity of frothy bloat in steers. Journal of Animal Science, Champaign, v. 68, n. 4, p. 1139-1150, 1990. 
BATISTA, H. A. M.; AUTREY, K. M.; THIESENHAUSEN, I. M. V. V. Comparative in vitro digestibility of forages by Buffalo, Zebu and Holstein cattle. Journal of Dairy Science, Champaign, v. 65, n. 5, p. 746-751, 1982.

CALLAWAY, E. S.; MARTIN, S. A. Effects of a Saccharomyces cerevisae culture on animal bacteria that utilize lactate and digest cellulose. Journal of Dairy Science, Champaign v. 80, n. 9, p. 2035-2044, 1997.

COELHO DA SILVA, J. F.; LEÃO, M. I. Fundamentos de nutrição de ruminantes. Piracicaba, Livroceres, 1979. $380 \mathrm{p}$.

EZEQUIEL, J. M. B. Exigência de proteina e minerais de bovídeos: frações endógenas. 1987. Tese (Doutorado em Zootecnia) - Universidades Federal de Viçosa, Viçosa, MG.

GALLOWAY, S. R. D. L.; GOETSCH, A. L.; PATIL, A.; FORSTER JÚNIOR, L. A.; JOHNSON, Z. B. Feed intake and digest by Holstein steer calves consuming lowquality grass supplemented with lasalocida or monensin. Canadian Journal of Animal Science, Ottawa, v. 73, n. 4, p. 869-879, 1993.

GOODRICH, R. D.; GARRETT, J. E.; GHAST, D. R. KIRICK, M. A.; LARSON, D. A.; MEISKE, J. C. Influence of monensin on the performance of cattle. Journal of Animal Science, Champaign, v. 58, n. 6, p. 1484-1498, 1984.

HUSSAIN, I.; CHEEKE, P. R. Evaluation of annual ryegrass straw corn juice silage with cattle and water buffalo: digestibility in cattle vs buffalo, and growth performance and subsequent lactational performance of Holstein heifers. Animal Feed Science and Technology, New York, v. 57, n. 3, p. 195-202, 1996.

JOHNSON JÚNIOR, J. C.; UTLEY, P. R.; MULLINIX JÚNIOR, B. G.; MERRILL, A. Effect of adding fat and lasalocid to diets of dairy cows. Journal of Dairy Science, Champaign, v. 71, n. 8, p. 2151-2165, 1988.

JOUANY, J. P.; MATHIEU, F.; SENAUD, J. Effect of Saccharomyces cerevisae and Arpergillus oryzae on the digestion of nitrogen in the rumen of defaunated and refaunated sheep. Animal Feed Science and Technology, New York, v. 75, n. 1, p. 1-13, 1998.

LEWIS, G. E.; HUNT, C. W.; SANCHEZ, W. K.; TREACHER, R.; PRITCHARD, G. T.; FENG, P. Effect of direct fed fibrolytic enzymes on the digestive characteristics of a forage-based diet fed to beef steers. Journal of Animal Science, Champaign, v. 74, n. 1, p. 3020-3028, 1996.

KENNEDY, P. M. Ruminal and intestinal digestion in Brahman crossbred and Hereford cattle fed alfafa or tropical pasture hay. Journal of Animal Science, Champaign, v. 55, n. 5, p. 1190-1199, 1982.

KNOWLTON, K. F.; ALLEN, M. S.; ERIKSON, P. S. Lasalocid and particle size of corn for dairy cows in early lactation: 2. effect on ruminal measurements and feeding behavior. Journal of Dairy Science, Champaign, v. 79, n. 4, p. 565-574, 1996.

MAEDA, E. M.; ZEOULA, L. M.; FUSSIGER, L. Degradabilidade ruminal da matéria seca e proteína bruta de alimentos volumosos em bubalinos e bovinos. In: REUNIÃO ANUAL DA SOCIEDADE BRASILEIRA DE ZOOTECNIA, 42., 2005, Goiânia. Anais... Goiânia: Universidade Federal de Goiás, UFG, 2005. p. 250-253.

MAEDA, E. M.; ZEOULA, L. M.; GERON, L. J. V.; BEST, J.; PRADO, I. N.; MARTINS, E. N.; KAZAMA, R. Digestibilidade e características ruminais de dietas com diferentes níveis de concentrado para bubalinos e bovinos. Revista Brasileira de Zootecnia, Viçosa, MG, v. 36, n. 3, p. 716-726, 2007.

MEHREZ, A. Z.; ORSKOV, E. R. A study of the artificial fiber bag technique for determining the digestibility of feeds in the rumen. Journal of Agricultural Science, Cambridge, v. 88, n. 3, p. 645-650, 1977.

MORAIS, J. A. S.; BERCHIELLI, T. T. REIS, R. A. Aditivos. In: BERCHIELLI, T. T.; PIRES, A. V.; OLIVEIRA, S.G. Nutrição de ruminantes. 2. ed. Jaboticabal: Funep, 2011. p. 580-616.

NATIONAL RESEARCH COUNCIL - NRC. Nutrient requirements of dairy cattle. 7. ed. Washington: National Academy of Press, 2001. 157 p.

NEWBOLD, J. Proposed mechanisms for enzymes as modifiers of ruminal fermentation. Scotland: University of Aberdeen, 1997. Available at: <http://dairy.ifas.ufl. edu/rns/1997/florida.pdf $>$. Accessed at: 04 nov. 2012.

NICODEMO, M. L. F. Uso de aditivos na dieta de bovinos de corte. Campo Grande: EMBRAPA Gado de Corte, 2001.

NOCEK, J. E. In situ and other methods to estimate ruminal protein end energy digestibility: a review. Journal Dairy Science, Champaign, v. 71, n. 8, p. 20512059, 1988.

ORSKOV, E. R.; McDONALD, I. The stimulation of protein degradability in the rumen from incubation measurements weighted according to rate of passage. Journal of Agriculture Science, Toronto, v. 92, n. 2, p. 499, 1979.

PEREIRA, E. S.; QUEIROZ, A. C.; PAULINO, M. F. CECON, P. R.; VALADARES FILHO, S. C.; MIRANDA, L. F.; ARRUDA, A. M. V.; FERNANDES, 
A. M.; CABRAL, L. S. Fontes nitrogenadas e uso de saccharomyces cerevisae em dietas à base de cana-deaçúcar para novilhos: consumo. Digestibilidade, balanço nitrogenado e parâmetros ruminais. Revista Brasileira de Zootecnia, Viçosa, MG, v. 30, n. 2, p. 563-572, 2001.

PEREIRA, J. R. A; ROSSI, P. Manual prático de avaliação nutricional de alimentos. Piracicaba: FEALQ, 1995. $34 \mathrm{p}$.

POORE, M. H.; ECK, T. P.; SWINGLE, R. S. Total starch and relative starch availability of feed grains. In: BIENNIAL CONFERENCE ON RUMEN FUNCTION, 20., 1989, Chicago. Proceedings...Chicago: University of Arkansas, 1989. CD-ROM.

POMAR, C.; BERNIER, J. F.; SEONE, F. R.; LATRILLE, L. High roughage rations with or without monensin for veal production. 2. Ration digestibility. Canadian Journal of Animal Science, Ottawa, v. 69, n. 2, p. 403-410, 1989.

PRADHAN, K.; BHATIA, S. K.; SANGWAN, D. C. Feed consumption pattern, ruminal degradation, nutrient digestibility and physiological reactions in buffalo and cattle. Indian Journal of Animal Sciences, New Delhi, v. 67, n. 2, p. 149-151, feb. 1997.

QUEIROZ, R. C.; BERGAMASCHINE, A. F.; BASTOS, J. F. P. O.; SANTOS, P. C.; LEMOS, G. C. Uso de produto à base de enzima e levedura na dieta de bovinos: digestibilidade dos nutrientes e desempenho em confinamento. Revista Brasileira de Zootecnia, Viçosa, MG, v. 33, n. 6, p. 1548-1556, 2004.

RESENDE, F. D.; QUEIROZ, A. C.; FONTES, C. A. A. Fibra em detergente neutro versus fibra em detergente ácido na formulação de dietas para ruminantes. Revista Brasileira de Zootecnia, Viçosa, MG, v. 24, n. 3, p. 342350, 1995.

RODRIGUES, P. H. M.; MATTOS, W. R. S.; MELOTTI, L.; RODRIGUES, R. R. Monensina e digestibilidade aparente em ovinos alimentados com proporções de volumoso/concentrado. Scientia Agrícola, Piracicaba, v. 58, n. 3, p. 449-455, 2001.

ROGERS, J. A.; DAVIS, C. L. Rumen volatile acid fatty production and nutrient utilization in steers fed a diet supplemented with sodium bicarbonate and monensin. Journal of Dairy Science, Champaign, v. 65, n. 6, p. 944952, 1982.

RUSSELL, J. B.; STROBEL, H. J. Effects of additives on in vitro ruminal fermentation: A comparison of monensin and bacitracin, another gram-positive antibiotic. Journal of Animal Science, Champaign, v. 66, n. 2, p. 552-558, 1988.
RUSSELL, J. B. Rumen microbiology and its role in ruminant nutrition. Ithaca: James B. Russell, 2002. 119 p.

SAMPAIO, A. A. M.; VIEIRA, P. F.; BRITO, R. M. Digestão total e parcial de nutrientes em bovinos alimentados com rações contendo levedura, uréia ou farelo de algodão. Revista Brasileira de Zootecnia, Viçosa, MG, v. 29, n. 2, p. 589-597, 2000.

SHARMA, D. D. Nutritional aspect in relation to meat production from buffaloes. In: WORLD BUFFALO CONGRESS, 2., 1988, New Delhi. Proceedings... New Delhi: Indian Council of Agricultural Research, 1988. p. 475-490.

SILVA, D. J.; QUEIROZ, A. C. Análise de alimentos. 3. ed. Viçosa: UFV/Imprensa Universitária, 2002. 235 p.

SOUZA, N. H.; FRANZOLIN, R.; RODRIGUES, P. H. M.; DEL CLARO, G. R. Efeitos de teores crescentes de fibra em detergente neutro na dieta sobre a digestão ruminal em bubalinos e bovinos. Revista Brasileira de Zootecnia, Viçosa, MG, v. 29, n. 5, p. 1565-1577, 2000.

UNIVERSIDADE FEDERAL DE VIÇOSA - UFV. Sistema de análise estatística e genética. Versão 8.0. Viçosa, MG: Universidade Federal de Viçosa, 1998.

VAN KEULEN, J.; YOUNG, B. A. Evaluation of acidinsoluble ash as a marker in ruminant digestibility studies. Journal of Animal Science, Champaign, v. 44, n. 2, p. 283287, 1977.

VAN SOEST, P. J. Nutritional ecology of the ruminant. 2. ed. London: Cornell University Press, 1994. 476 p.

VAN SOEST, P. J.; ROBERTSON, J. B.; LEWIS, B. A. Methods for dietary fiber, neutral detergent fiber, and nonstarch polysaccharides in relation to animal nutrition. Journal of Dairy Science, Champaign, v. 74, n. 12, p. 3583-3597, 1991.

ZEOULA, M. L.; BELEZE, J. R. F.; GERON, L. J. V.; MAEDA, E. M.; PRADO, I. N.; PAULA, M. C. Digestibilidade parcial e total de rações com a inclusão de ionóforo ou probiótico para bubalinos e bovinos. Revista Brasileira de Zootecnia, Viçosa, MG, v. 37, n. 3, p. 563-571, 2008.

ZINN, R. A.; PLASCENCIA, A.; BARAJAS, R. Interaction of forage level and monensin in diets for feedlot catlle on growth performance and digestive function. Journal of Animal Science, Champaign, v. 72, n. 9, p. 2209-2215, 1994. 